\title{
On the use of the NACA0021 and the S1046 blade profiles with a hydro Darrieus turbine under the typical operating conditions of the Nile River
}

\author{
A. Abdellatif, S. Shaaban \\ Mechanical Engineering Department, College of Engineering and Technology- \\ Cairo Campus, Arab Academy for Science, Technology and Maritime Transport \\ (AASTMT)
}

\begin{abstract}
:
Nowadays there is an increase in the demand on renewable energy due to the limitations of the other non-renewable sources. Using the kinetic energy of a flowing water is becoming a great alternative for energy harvesting. Darrieus turbine performance depends on many parameters such as the tip speed ratio, solidity and blade geometry. In the present research, great attention was given for the feasibility of using the blades profiles NACA0021 and S1046 with Darrieus hydro turbine for the Nile River. Unsteady Reynolds Averaged Naiver-Stokes Equation (URANS) with realizable $\mathrm{k}-\varepsilon$ turbulence model and enhanced wall treatment was used to simulate the unsteady turbulent flow through the turbine. The finite volume CFD code Fluent was utilized as a solver. The results show that NACA0021 is more efficient to use under the typical operating conditions of the Nile River compared to the S1046 blade profile.
\end{abstract}




\begin{tabular}{|l|l|}
\hline \multicolumn{2}{|l|}{ Nomenclature: } \\
\cline { 1 - 2 } A & cross section area of turbine in flow stream $\left(\mathrm{m}^{2}\right)$ \\
$\mathrm{C}$ & chord length of blade $(\mathrm{m})$ \\
$C_{P}$ & Power coefficient \\
$C_{T}$ & Torque coefficient \\
$\mathrm{D}$ & diameter of the rotor $(\mathrm{m})$ \\
$F_{D}$ & Drag (N) \\
$F_{L}$ & Lift $(\mathrm{N})$ \\
$F_{N}$ & Normal force $(\mathrm{N})$ \\
$F_{T}$ & Tangential force $(\mathrm{N})$ \\
$\mathrm{H}$ & Height of rotor \\
$\mathrm{N}$ & Number of blades of the turbine \\
$\mathrm{P}$ & Power (W) \\
$\mathrm{T}$ & Torque (N m) \\
$\mathrm{W}$ & Blade relative velocity $(\mathrm{m} / \mathrm{s})$ \\
$V_{0}$ & Free-stream velocity $(\mathrm{m} / \mathrm{s})$ \\
$Y^{+}$ & Non-dimensional wall distance \\
$\alpha$ & Blade's azimuth position $\left({ }^{\circ}\right)$ \\
$\varepsilon$ & Turbulent dissipation $\left(\mathrm{m}^{2} \cdot \mathrm{s}^{-3}\right)$ \\
$\lambda$ & Tip-speed ratio \\
$\rho$ & Fluid density $\left(\mathrm{kg} \cdot \mathrm{m}^{-3}\right)$ \\
$\mathrm{NACA}$ & National Advisory Committee for Aeronautics \\
$\mathrm{URANS}$ & Unsteady Reynolds Averaged Naiver-Stokes Equation \\
VAWT & Vertical Axis Wind Turbine \\
VAT & Vertical Axis Turbine \\
\hline
\end{tabular}

\section{Introduction}

At the present time renewable energy is considered a global trend for power generation due to the lack of fossil fuel and the need to protect the environment. One of the renewable energy resources that have been used for many years is the hydro power. This power can be converted into mechanical energy using hydro turbines. Among the different turbine designs, the H-rotor Darrieus turbine can be used to extract energy from the low velocity water streams. This turbine was invented in 1931 by Georges Jean Marie Darrieus and it is typically known as an air 
turbine. Its working principle is based on extracting energy from a flowing fluid through a vertical axis turbine (VAT) [1]. In the beginning of 1970-1980, Canada and the United States provided great attention in building many prototypes of the Darrieus turbine which proved its efficiency [2]. The development of modern vertical axis wind turbines (VAWT) requires investigations of the optimum design parameters and performance prediction before fabrication [3]. Castelli et al [4] experimentally and numerically studied the performance of a micro Darrieus turbine in a wind tunnel. Almohammadi et al [5] introduced three alternative methods for mesh independence test in order to understand the convergence behavior of the turbine's numerical simulation. Mohamed et al. [6] numerically examined 25 different airfoils to define the best blade profile for a Darrieus VAWT. Shih et al. [7] numerically investigated the effect of the pitch angle on the Darrieus turbine performance using the realizable k- $\varepsilon$ turbulence model. Meanwhile, Menter [8] simulated the turbine performance using the transitional SST K- $\omega$ turbulence model. $\mathrm{Du}$ and $\mathrm{Wu}[9]$ reported that the realizable $\mathrm{k}-\varepsilon$ turbulence model gives good results in simulating the unsteady aerodynamic performance of wind turbines.

Investigations for using the straight blade hydro turbine started by Fraenkel, and Musgrove in 1979 [10], and Hilton in 1982 [10]. The application of Darrieus turbine for converting the energy of third world countries rivers was introduced by Hilton [10]. Khan et al. [11] presented a detailed overview for various hydrokinetic rotors with fluid dynamic performance. They focused on the main design characteristics for straight bladed Darrieus turbine using the stream tube modeling. Gretton et al. [12] examined the variation of the hydrodynamic performance of vertical axis turbine with tip speed ratio for a number of configurations. They showed the advantages of the variable pitch operation while limiting the angle of attack. In recent years, great attention was given for Darrieus straight blade hydro turbine. Prabhu et al. [13] built a simple single stream tube model to predict the coefficient of performance for Darrieus hydro turbine rotor. Stream tube models are momentum models based on Glauert's blade element theory [14]. It cannot predict the performance at all tip speed ratios and cannot be used for high rotor solidities. Lain and Osorio [15] presented unsteady flow simulation for the flow across a vertical axis turbine. They demonstrated that the computational fluid dynamics (CFD) models can effectively predict the hydrodynamic performance of turbines. Fleisinger et al. [16] implemented a flow-driven approach in CFD simulation, where the turbine rotation is governed by the standstill stream velocity. Gorle et al. [17] investigated the flow and performance of H-Darrieus hydro turbine in a confined flow simulation using the $\mathrm{k}-\omega$ turbulence model.

The objective of the present work is to simulate a hydro VAT for the operating condition of the Nile River in Egypt. This is because a Darrieus turbine was proven to generate $5 \mathrm{~kW}$ in the Kurushima Straits of Japan where the maximum speed of the tidal current exceeds $5 \mathrm{~m} / \mathrm{s}$ Fig. 1 [19]. The Nile River is the longest river in the 
world, which gives great attention for use of this hydropower in power generation applications. The use of small-scale hydro turbines in places having high water currents will help in providing electricity in a simple and clean way, especially for remote areas on the Nile River.
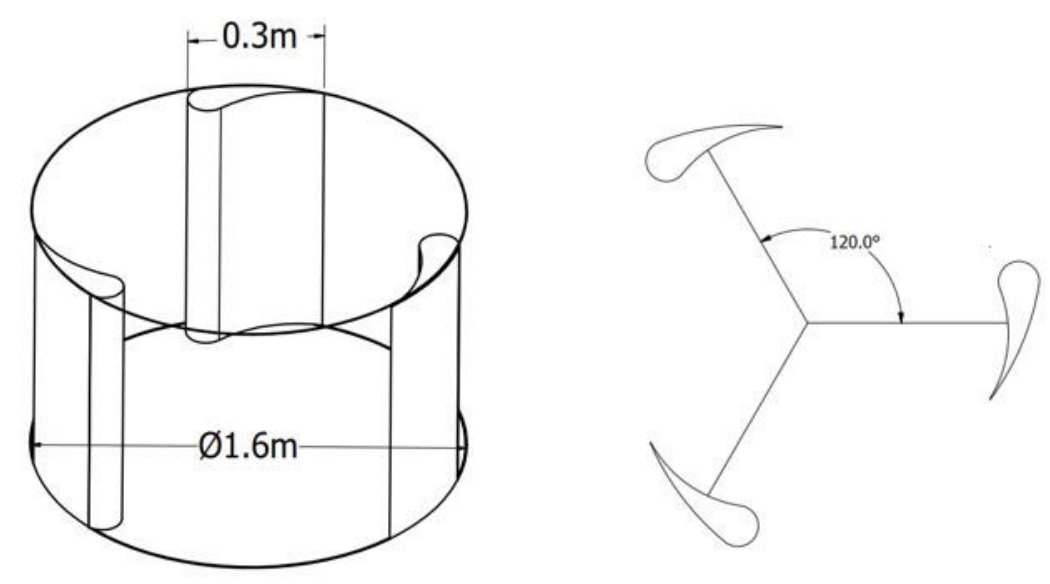

Fig. 1 Kurushima Darrieus turbine in Japan [19]

\section{$\underline{\text { Numerical Model }}$}

Navier-Stokes equations have been used for more than a century ago to simulate the fluid flow in different applications. A CFD simulation of the Darrieus turbine is complicated due to the high time-dependency nature of the flow around the airfoil. Accordingly, great attention must be given to check the full numerical simulation procedure. Moreover, the results must be validated by comparison with available test data. Consequently, the present numerically investigated Darrieus turbine has the same dimensions tested by Castelli [20]. The turbine's main geometrical parameters are given in Table 1. The turbine was investigated under the same test conditions of Raciti Castelli where the wind speed is constant at $9 \mathrm{~m} / \mathrm{s}$ and the turbine solidity is $\sigma=0.25$.

The turbine solidity $(\sigma)$ is defined as, $\sigma=\frac{N c}{D}$

Where $N$ is the number of blades, $C$ is the chord length and $D$ is the diameter of the turbine rotor. 
Table 1 Geometric parameters of the investigated turbine:

\begin{tabular}{|l|l|}
\hline Parameter & Values used \\
\hline Chord length $(\mathrm{C})$ & $0.0858 \mathrm{~m}$ \\
Number of & 3 \\
blades $(\mathrm{N})$ & $0.515 \mathrm{~m}$ \\
Rotor radius $(\mathrm{R})$ & 0.25 \\
Solidity $(\sigma)$ & \\
\hline
\end{tabular}

VAT straight bladed Darrieus type is one of the most famous VAWT among the different turbine designs. It can be used with either air or water. Despite the simplicity of the Darrieus straight bladed design, it permits the occurrence of high unsteady turbulent flow. It's shown from velocity triangle on blades at different azimuth angle Fig. 2, that the resultant velocity was generated from combination of both free stream velocity $\boldsymbol{V}_{\mathbf{0}}$ and tangential velocity which equal to $\omega R$.

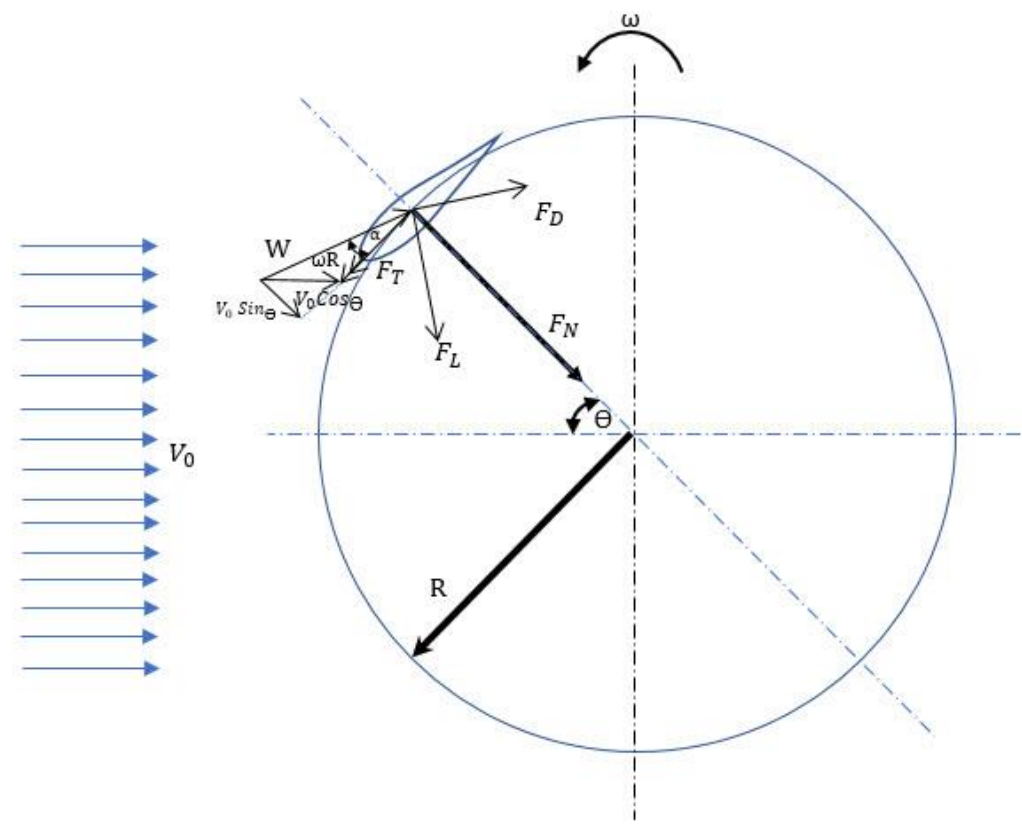

Fig. 2 Forces and velocities on Darrieus rotor

The turbine tip speed ratio $(\lambda)$ which is the ratio between tangential velocity and free stream velocity expressed by,

$\lambda=\frac{\omega R}{V_{0}}$ 
There is a relation between the azimuth angle $\theta$, the angle of attack $\propto$ and the speed ratio $\lambda$ from the velocity triangle shown in Fig. 2, this relation is as follows:

$\propto=\tan ^{-1}\left(\frac{\sin \theta}{\lambda+\cos \theta}\right)$

The fluid flow over the airfoil will generate a lift force $F_{L}$ and a drag force $F_{D}$. These forces can be resolved to get the tangential force $F_{T}$ and axial force $F_{N}$ as shown in Fig. 2. The tangential force is responsible for the torque and power generated from the Darrieus turbine. For a Darrieus rotor with a height $\mathrm{H}$, and incoming fluid velocity $V_{0}$, the turbine power and torque coefficients can be expressed by:

$$
\begin{aligned}
C_{T} & =\frac{T}{\frac{1}{2} \rho A R V_{0}^{2}} \\
C_{p} & =\frac{P}{\frac{1}{2} \rho A V_{0}{ }^{3}}
\end{aligned}
$$

The simulation of the turbine performance requires a spatial discretization of the computational domain by generating a mesh. The mesh generation was performed on Pointwise software using a high-quality discretization hybrid mesh of both structured and unstructured meshes as shown in Fig. 3. The structured mesh was placed around the blades where the critical flow phenomena will take place. The unstructured mesh was used for the rest of the computational domain to reduce the computation time while maintaining the accuracy of the results Fig. 4 shows more details of the mesh configuration.

Fluent used as a solver with 2nd order upwind characteristics for all parameters, through transient sliding mesh model that runs 7 complete revolutions. Obtained results from the last two revolutions. For time step analysis test, it was performed by decreasing time step per degree of rotation. Power coefficient relative variation resulted was below $2 \%$ for using 1 degree of rotation/ time step, also this time step was used to minimize simulation time while sustaining all the results independent on the mesh size.

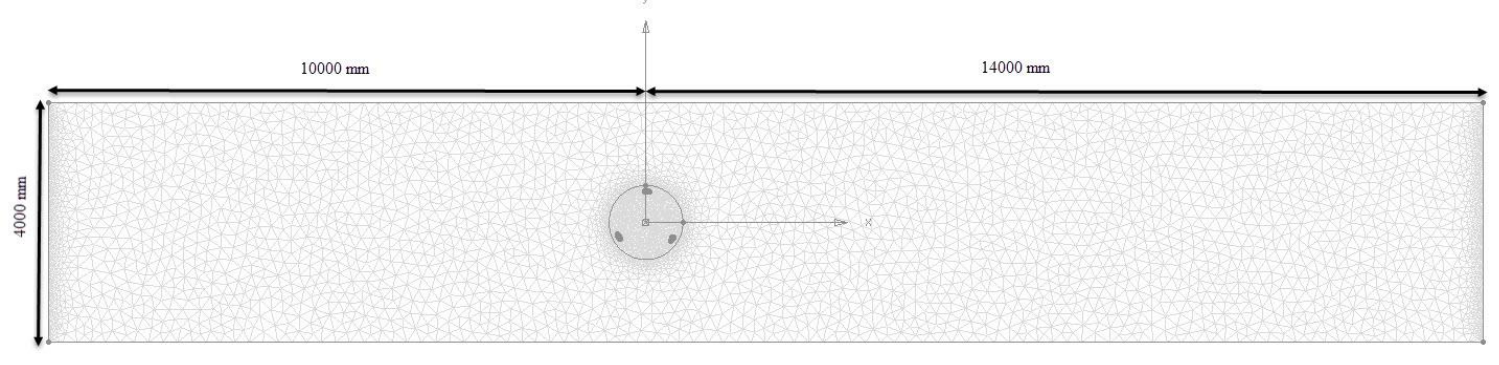

Fig. 3 Whole domain mesh around the VAWT 

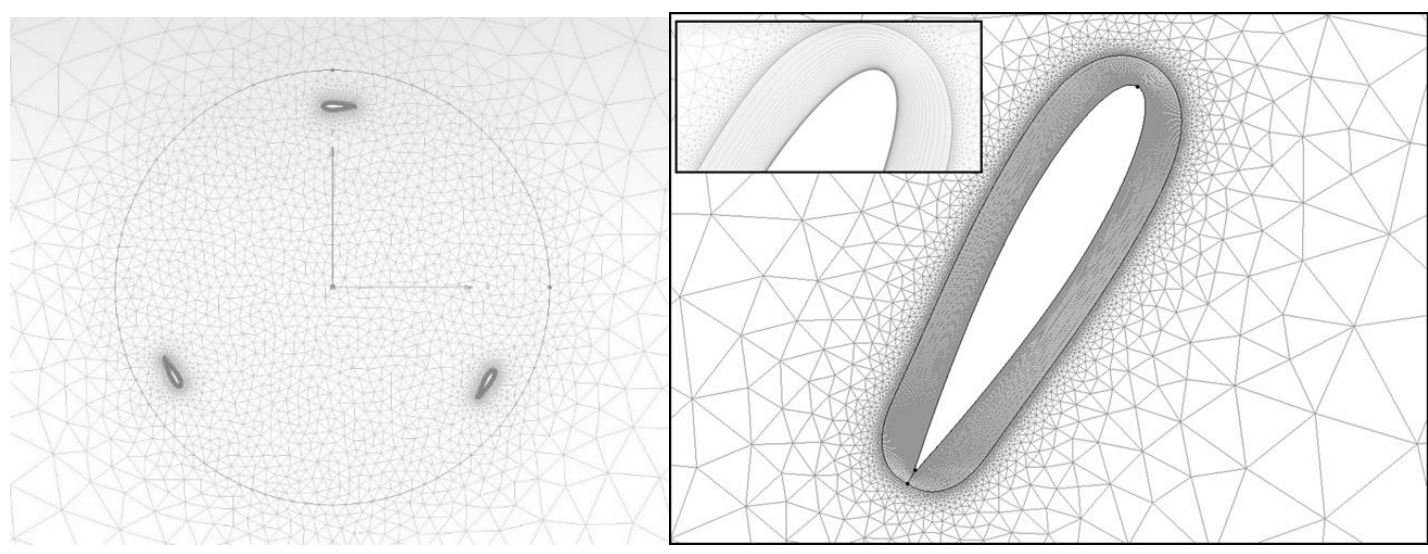

Fig. 4 Mesh around the rotor (left) and structure mesh around the blades (right)

Different stages of enhancements were applied to the mesh in order to ensure that the non-dimensional wall distance $Y^{+}<1$ in all simulated cases first cell height was 0.00019998. Despite that, the CFD results may deviate from the experimental results due to many other reasons (e.g., the mesh size). Accordingly, the numerical results should be validated by comparing the simulation results with the available experimental results. Validation of the present model was assured by performing two tests; namely mesh and time independence tests. After performing the two tests, the numerical results were compared to the experimental results published before [4]. The mesh size independence test was performed by regularly increasing the $2 \mathrm{D}$ mesh quality and density from 100000 to 250000 . The results of the mesh size have a relative variation of the power coefficient is below $1 \%$ when using a mesh size above 200000 cells Fig. 5. Accordingly, a mesh size range of 220000 to 230000 cells was used in the present work to minimize the simulation time while maintaining all results independent of the mesh size.

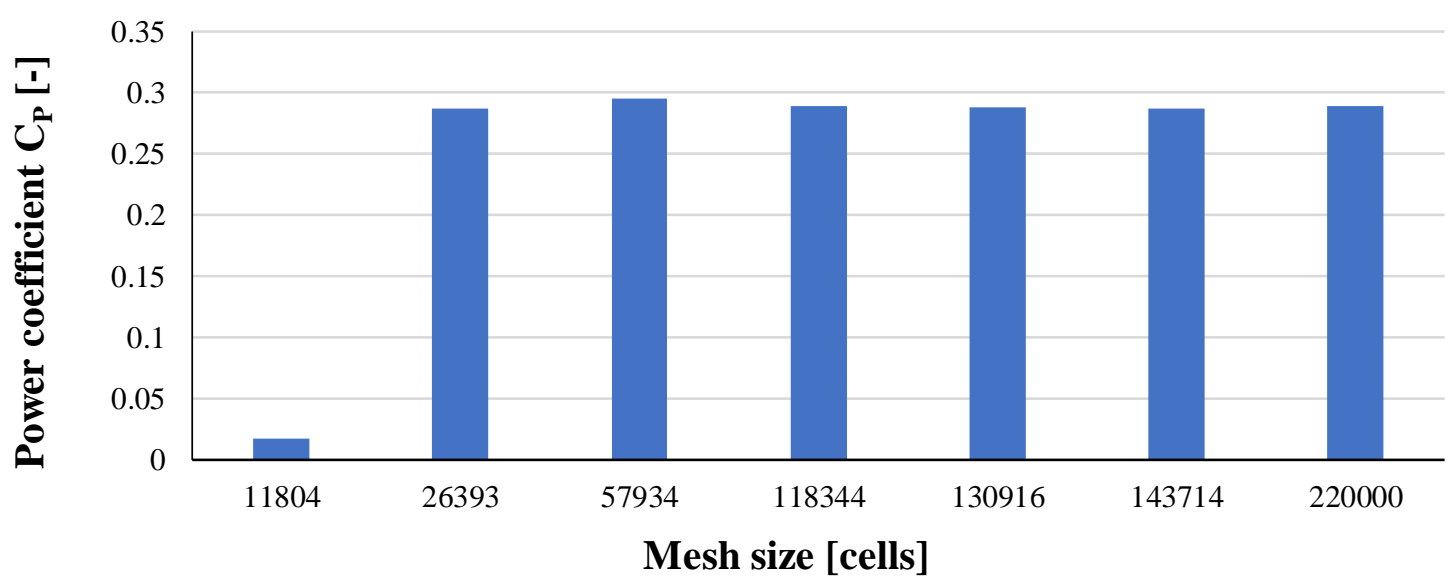

Fig. 5 Mesh independence test 
The Realizable k- $\varepsilon$ turbulence model was used to simulate the viscous fluid flow through the turbine. This model uses a new transport equation for the turbulent dissipation rate and it expresses the turbulence properties as a function of the mean flow rather than being constant as in the standard model. This allows for additional constraints on the normal stress and gives better simulation results for the swirling flow which involves separation [6]. The present numerical model was validated by comparison with the published experimental results of Castelli et al. [4] and numerical results of Mohamed et al. [6] for the H-rotor Darrieus turbine NACA0021 blade profile as shown in Fig. 6.

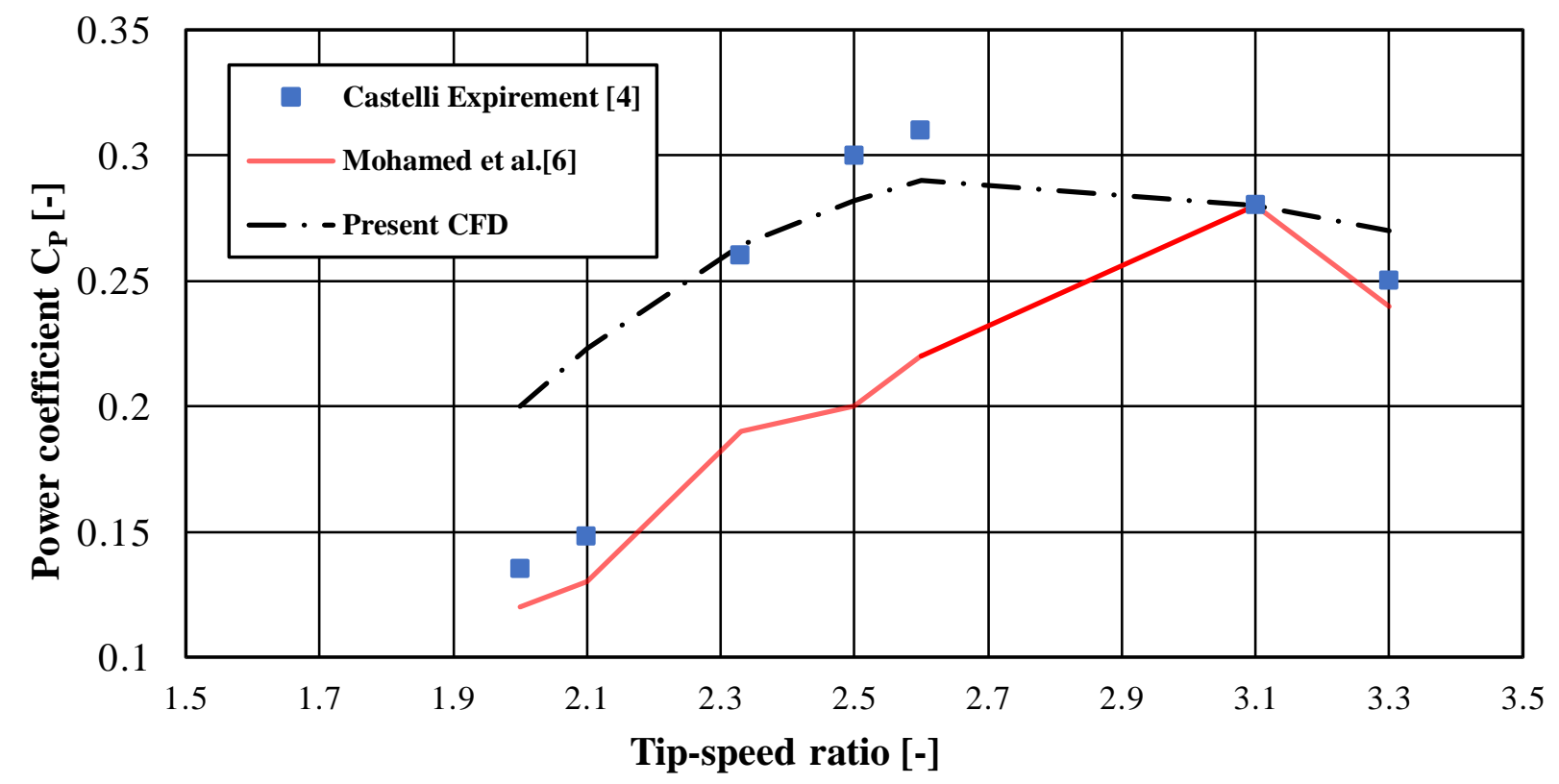

Fig. 6 Performance H-rotor Darrieus turbine using different $\lambda$

\section{$\underline{\text { Results and Discussion }}$}

Investigations were the geometry for the NACA0021 and S1046 blade profiles using 2D simulation. Fig. 7 shows the investigated blade profiles. The free stream velocity data taken from the National Water Research Center where the Nile water average velocity over the year after Assuit Barrage equals $1.1 \mathrm{~m} / \mathrm{s}$ [21]. The two blades were simulated under the same circumstances to monitor the changes in different aspects (pressure, velocity and turbulent intensity). The main concern while using the CFD was monitoring the behavior with reducing the Reynolds number to capture the stall phenomena. The laminar boundary layer is relatively very sensitive to pressure gradients. Accordingly, the realizable $\mathrm{k}-\varepsilon$ turbulence model was used. 


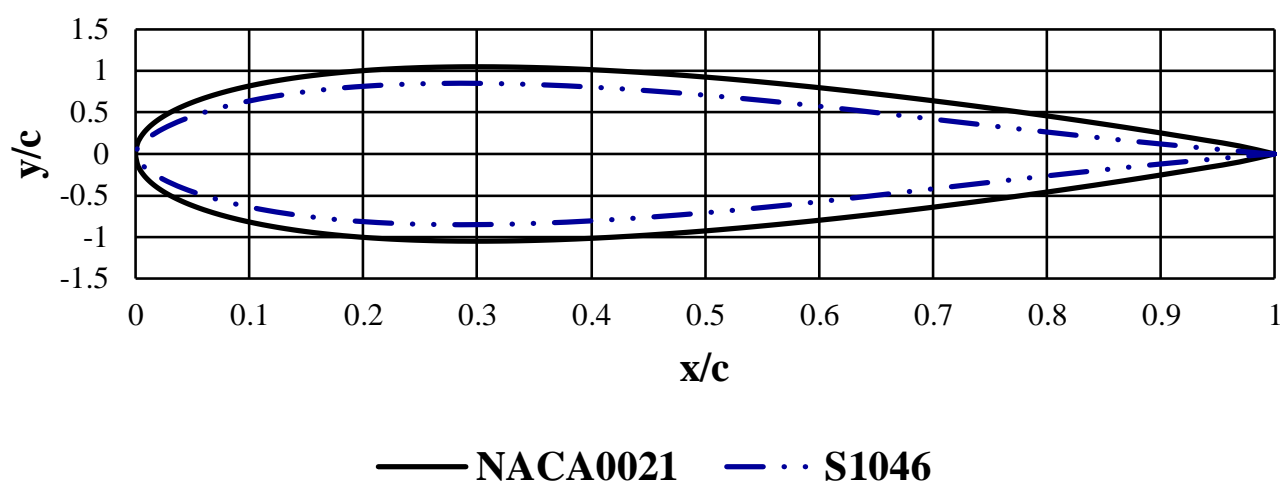

Fig. 7 Blade profiles comparison

The results obtained from the CFD show that the S1046 blade profile has a lower pressure on the suction side compared to the NACA0021 as shown in Fig. 8. This means higher velocity and Reynolds number on the suction side of the NACA0021 as shown in Fig. 9. Meanwhile, the turbulent intensity is comparable for both profiles in Fig. 10. The higher Reynolds number on the suction side of the NACA0021 is crucial for the turbine performance near stall. This is because higher Reynolds number means less stall on the suction side of the NACA0021 compared to the S1046 blade profile.
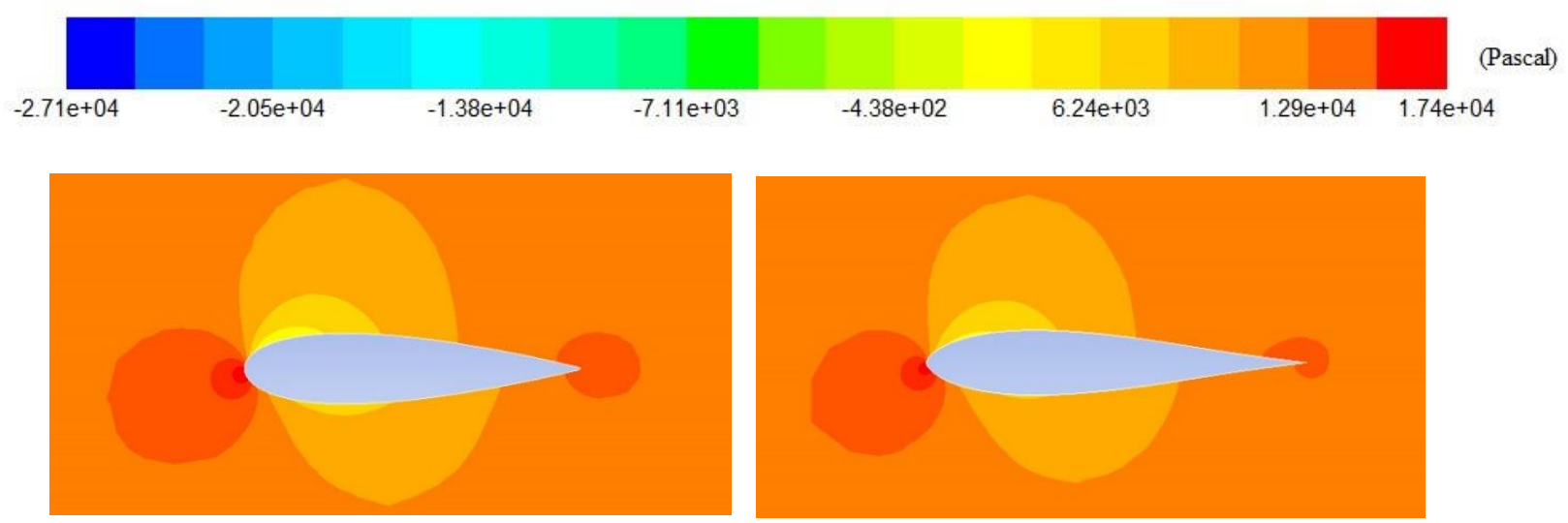

Fig. 8 Pressure profile on the NACA0021 (left) and S1046 (right) 
S. Shaaban /et al/ Engineering Research Journal 160 (December 2018) M42 - M55
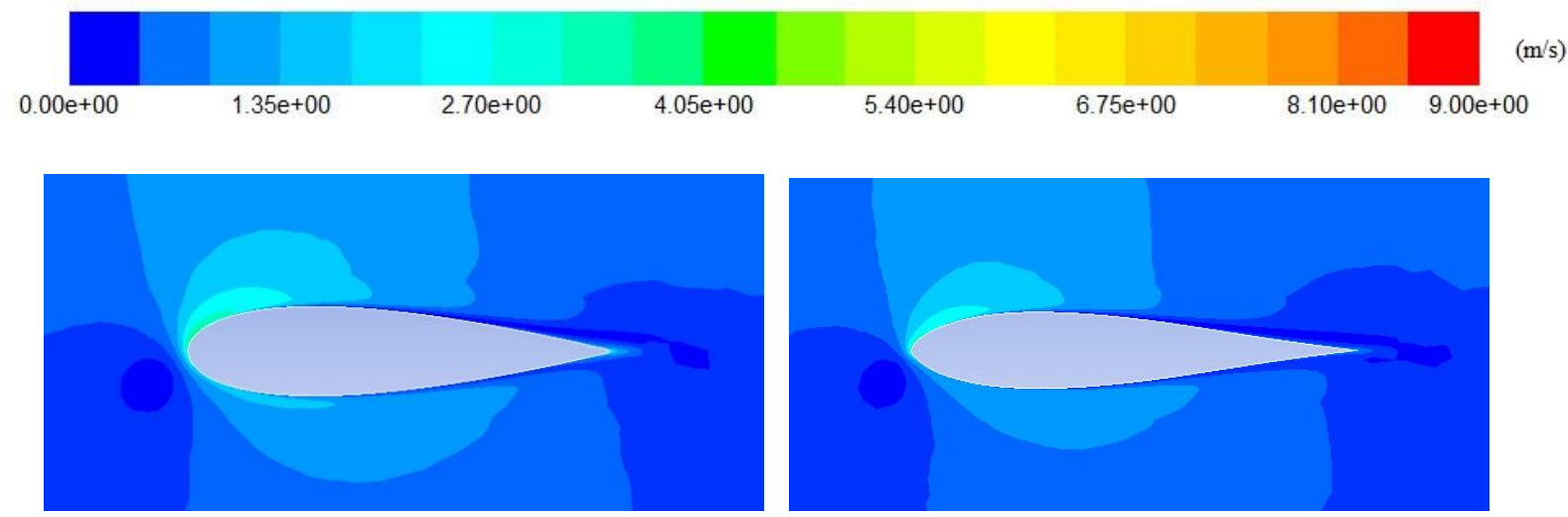

Fig. 9 Velocity profile on the NACA0021 (left) and S1046 (right)
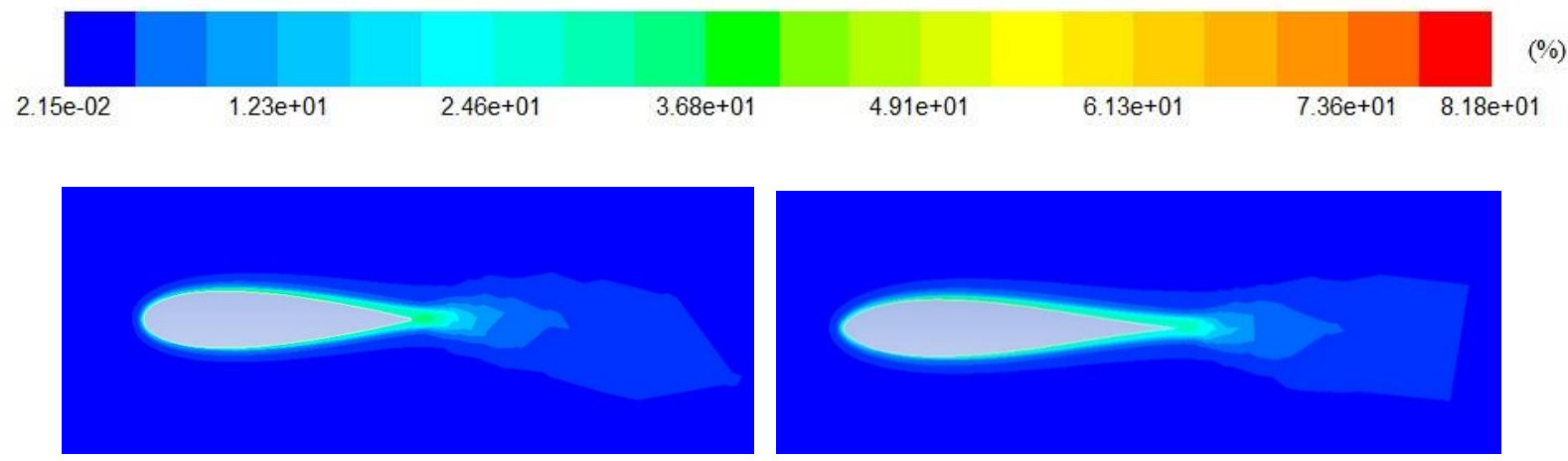

Fig. 10 Turbulent Intensity profile on the NACA0021 (left) and S1046 (right)

Investigating of the performance over different tip speed ratios shows that both profiles have the same power coefficient at a tip speed ratio equals 2.8 as shown in Fig. 11. The NACA 0021 have better results at lower tip speed ratios over the S1046 due to its higher local Reynolds number on the blade suction side. Accordingly, the blade profile NACA0021 is better at part load performance while S1046 is better at working on design point and free, so its recommended to use NACA0021 with a hydro Darrieus turbine in the Nile River. This is because the investigated free stream velocity of $1.1 \mathrm{~m} / \mathrm{s}$ [21] represents the maximum attainable water velocity and the water velocity will be lower than that for other periods of the year. 


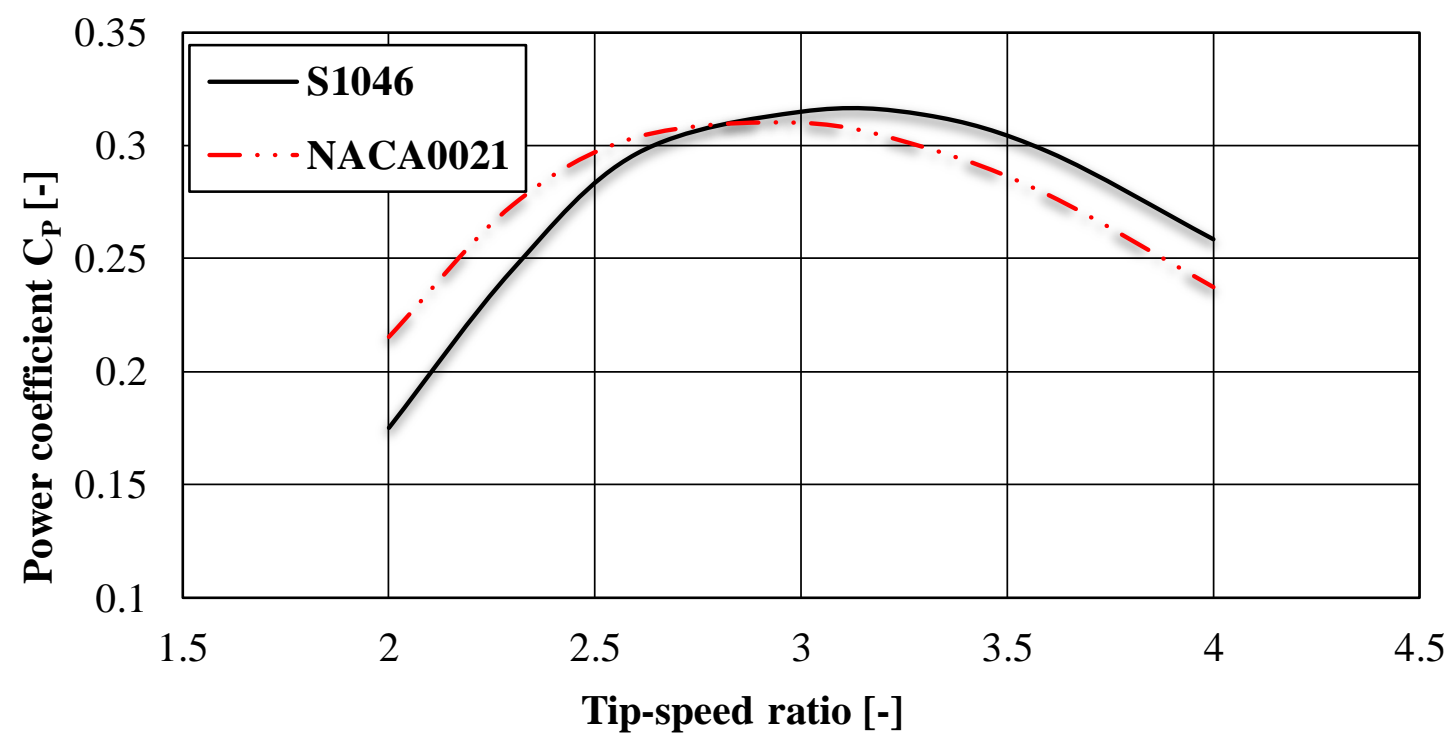

Fig. 11 Performance curve using NACA0021 and S1046 profile

The relation between the torque coefficient and flow time for a tip speed ratio equals 2.6 as it has the highest power coefficient is shown in Fig. 12. The maximum torque coefficient is higher for the S1046 blade profile. However, its minimum torque coefficient is also lower than that the NACA0021 blade profile. Consequently, the averages torque coefficient of the NACA0021 blade profile is lower than that of the S1046 at tip speed ratio equals 2.6.

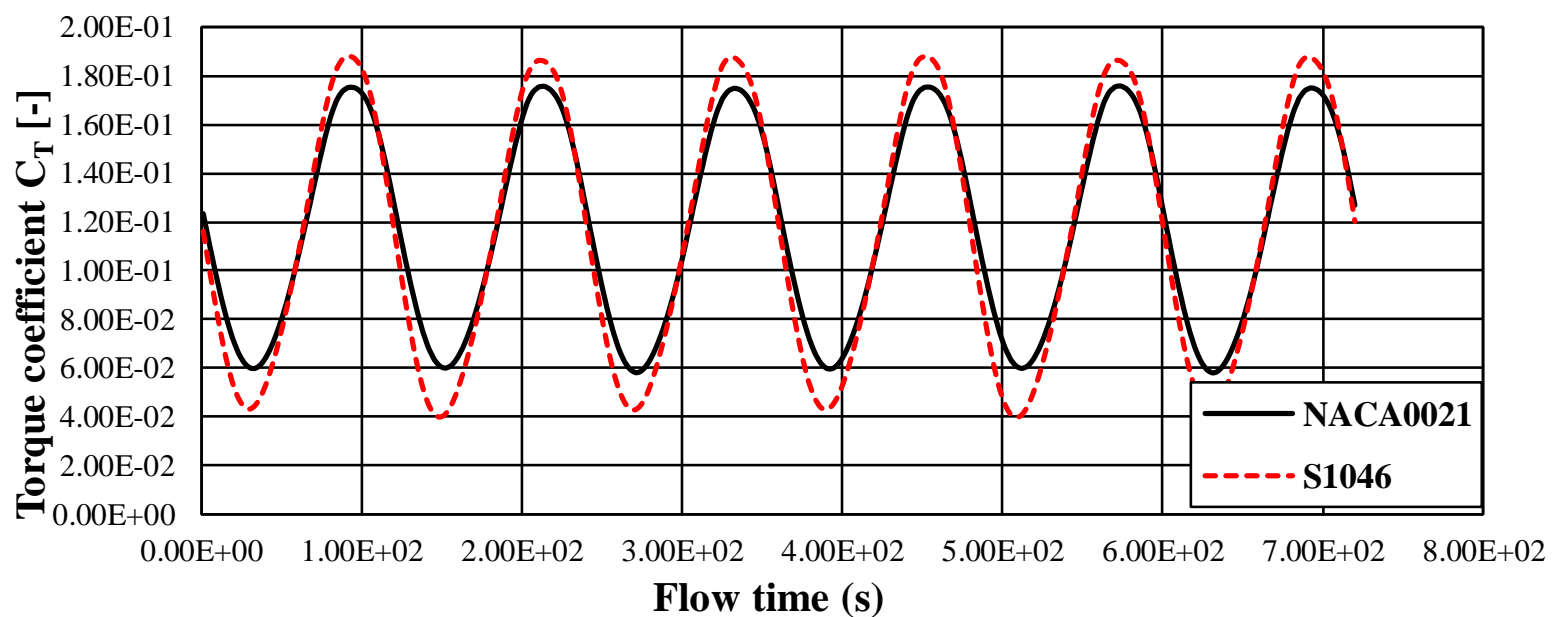

Fig. 12 Variation of the torque coefficient for the S1046 and NACA0021 blade profiles at $\lambda=2.6$ 


\section{Conclusions and future works}

The low speed Darrieus hydro turbine is one feasible solution to overcome the problem of lack of electric power supply in remote area. A great attention is necessary to be given for renewable hydropower energy and its effect on power development. Therefore, this study focuses on covering a new method for introducing regular $\mathrm{H}$-Darrieus wind turbine in water application.

The current study includes 2D simulation investigation over the H-Darrieus to predict the power output resulted from the NACA0021 and S1046 blade profiles. The dependent solution was reached after many refinements trials to ensure more realistic prediction for the gained results. The present numerical results show that the NACA0021 is more feasible for use under the typical operating conditions of the Nile River compared to the S1046 blade profile.

Its recommended for future work to perform proper experimental and numerical simulation for a 3D turbine model. 


\section{References:}

1. Darrieus, G.J.M. Turbine having its rotating shaft transverse to the flow of the current, United States Patent Office, Patent no. 1835018, 1931.

2. Peace S. Another approach to wind (cover story). Mech Eng. 2004;126(6):28-31.

3. Islam M, David S.K. Ting, A. Fartaj, Aerodynamic models for Darrieus-type straight-bladed vertical axis wind turbines, Renew. Sustain. Energy Rev.12 (2008) 1087-1109

4. Castelli MR, Englaro A, Benini E. The Darrieus wind turbine: proposal for a new performance prediction model based on CFD. Energy 2011;36(6) 4919-34.

5. K. Almohammadi, D. Ingham, L. Ma and M. Pourkashan, "Computational Fluid Dynamics (CFD) Mesh Independency Techniques for a Straight Blade Vertical Axis Wind Turbine," Energy, vol. 58, pp. 483-493, 2013.

6. Mohamed, M.H., Ali, A.M., Hafiz, A.A., 2015. CFD analysis for H-rotor Darrieus turbine as a low speed wind energy converter. Int. J. 18 (1),1-13,

7. Shih T, Liou WW, Shabbir A, Yang Z, Zhu J. A new k- $\varepsilon$ eddy viscosity model for high Reynolds number turbulent flows. Computers Fluids Vol. 24, No. 3, pp. 227-238.

8. Menter FR. Zonal Two equation k- $\omega$ turbulence models for aerodynamic flows. In: 24th fluid dynamics conference, no. AIAA-93-2906, AIAA, Orlando, Florida, USA 1993. pp. 1-21.

9. Gang Du and Kau Wu. (2015). Unsteady Flow Numerical Simulation of Vertical Axis Wind Turbine. Procedia Engineering. 99 (2015). 734-740.

10. Fraenkel, P. and P. Musgrove. Tidal and river current energy systems. in International conference on future energy concepts. 1979.

10. D. J. Hilton, 1983, - Performance of a Darrieus water turbine at various solidities, Eighth Australian fluid mechanics conference, university of Newcastle, N.S.W

11. M. J. Khan, M. T. Iqbal and J. E. Quaicoe, "Design Considerations of a Straight Bladed Darrieus Rotor for River Current Turbines," 2006 IEEE International Symposium on Industrial Electronics, Montreal, Que.,2006, pp.1750-1755.

12. G. Gretton, T. Bruce and D. Ingram, "Hydrodynamic Modelling of a Vertical Axis Tidal Current Turbine using CFD," Proceedings of the 8th European Wave and Tidal Energy Conference, pp. 468-476, 2009.

13. Prabhu S.V., Vimal Patel, Himanshu Chaudhari, 2013, -Performance Prediction of H-Type Darrieus Turbine by Single Stream Tube Model for Hydro Dynamic Application, International Journal of Engineering Research and Technology (IJERT), ISSN: 2278-0181, Vol. 2 Issue 3.

14. H. Glauert, "The elements of aerofoil and airscrew theory", Cambridge University Press, 2nd Edition 1947. 
15. S. Lain and C. Osorio, "Simulation and Evaluation of a Straight-Bladed cDarrieus-type Cross Flow Marine Turbine," Journal of Scientific and Industrial Research (JSIR), vol. 69, no. 12, pp. 906 - 912, 2010.

16. Fleisinger, Matjaž and Vesenjak, Matej and Hriberšek, Matjaz. (2014). Flow Driven Analysis of a Darrieus Water Turbine. Strojniski Vestnik/Journal of Mechanical Engineering. 60. 769-776.

17. AJagan, Gorle and Chatellier, Ludovic and Pons, Frederic and Malick, Ba. (2016). Flow and performance analysis of H-Darrieus hydro turbine in a confined flow: A computational and experimental study. Journal of Fluids and Structures. 66. 382-402.

18. Kihon, S., and Shiono Mitsuhiro., -Electric power generations from tidal currents by Darrieus turbine at Kurushima straitsll. Trans IEEE Japan, vol.112- D, no. 6 (1992). 530- 8.

19. Castelli, M.R., Ardizzon, G., Battisti, L., Benini, E., Pavesi, G., 2010. Modeling strategy and numerical validation for a Darrieus vertical axis micro-wind turbine. in ASME International Mechanical Engineering Congress and Exposition.

21. Hydraulics Research Institute, National Water Research Center, Numerical Modelling Department (2018). 